\title{
The influence of pulmonary artery morphology on the results of operations for major aortopulmonary collateral arteries and complex congenital heart defects
}

\author{
Massimo Griselli, MD, MS, FRCS \\ Simon P. McGuirk, BMedSci (Hons), MRCS (Ed) ${ }^{a}$ \\ David S. Winlaw, MD, FRACS ${ }^{a}$ \\ Oliver Stümper, $\mathrm{MD}, \mathrm{PhD}^{\mathrm{b}}$ \\ Joseph V. de Giovanni, MD, FRCP, FRCPCH \\ Paul Miller, MRCP \\ Rami Dhillon, MRCP, MRCPCH \\ John G. Wright, MA, FRCP, FRCPCH \\ David J. Barron, MD, MRCP, FRCS (CTh) ${ }^{\text {a }}$ \\ William J. Brawn, FRCS, FRACS ${ }^{\mathrm{a}}$
}

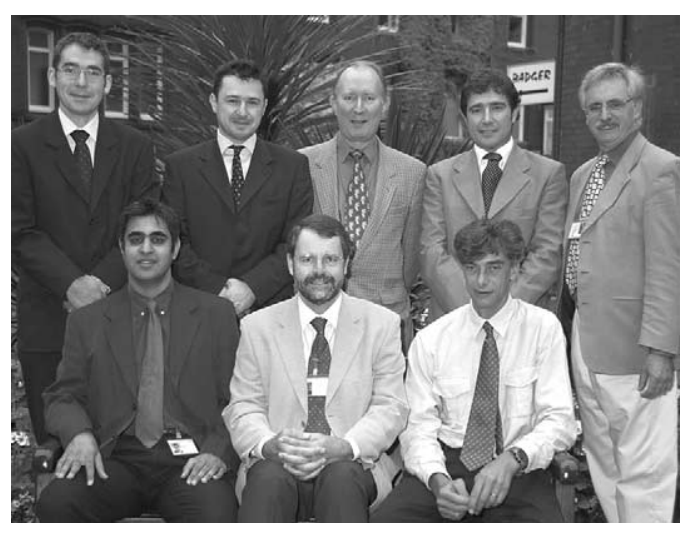

Objective: Congenital heart defects with major aortopulmonary collateral arteries show marked variability in the size and distribution of native pulmonary arteries. We sought to classify the size and distribution of native pulmonary arteries and to determine their influence on surgical outcome.

Methods: Between 1989 and 2002, 164 patients underwent surgical intervention for congenital heart defects with major aortopulmonary collateral arteries (median age, 10 months). Three patterns of native pulmonary arteries were identified: intrapericardial native pulmonary arteries present (group I); confluent intrapulmonary native pulmonary arteries without intrapericardial native pulmonary arteries (group II); and nonconfluent intrapulmonary native pulmonary arteries (group III). Thirty-seven $(23 \%)$ patients had single-stage and $76(47 \%)$ patients had multistage complete repair. Thirty (18\%) patients await septation, and 8 (5.0\%) patients are not septatable. Follow-up is $98 \%$ complete (median follow-up, 5.8 years).

From the Departments of Cardiac Surgery ${ }^{\mathrm{a}}$ and Cardiology, ${ }^{\mathrm{b}}$ Diana, Princess of Wales Children's Hospital, Birmingham, United Kingdom.

Received for publication May 2, 2003; revisions requested Aug 20, 2003; accepted for publication Aug 25, 2003.

Address for reprints: William J. Brawn, FRCS, FRACS, Department of Cardiac Surgery, Diana, Princess of Wales Children's Hospital, Steelhouse Ln, Birmingham B4 6NH, United Kingdom (E-mail: william.brawn@bch.nhs.uk).

J Thorac Cardiovasc Surg 2004;127:251-8 $0022-5223 / \$ 30.00$

Copyright () 2004 by The American Association for Thoracic Surgery

doi:10.1016/j.jtcvs.2003.08.052
Results: In the 164 patients there were $15(9.1 \%)$ early and $12(7.3 \%)$ late deaths. Early mortality after complete repair was $4.4 \%(\mathrm{n}=5)$. Actuarial survival was $90 \%$ $\pm 3 \%$ and $85 \% \pm 4 \%$ at 1 and 10 years, respectively. Actuarial freedom from surgical or catheter reintervention in septated patients was $77 \% \pm 4 \%$ and $45 \% \pm$ $8 \%$ at 1 and 10 years, respectively. On multivariate analysis, the morphology of the native pulmonary arteries was the only factor that influenced actuarial survival after complete repair $(P=.04)$. Group III had the highest risk of death after septation $(P=.008)$. Group II fared better than group III after the initial operation $(P<.05)$.

Conclusions: Current classifications of congenital heart defects with major aortopulmonary collateral arteries are based on the presence or absence of intrapericardial pulmonary arteries. We have identified a subgroup without intrapericardial native pulmonary arteries but with confluent intrapulmonary native pulmonary arteries. This group has a better outcome than those with nonconfluent intrapulmonary native pulmonary arteries. 


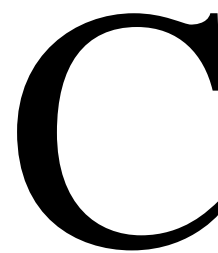

ongenital heart defects (CHDs) with major aortopulmonary collateral arteries (MAPCAs) are characterized by marked morphologic variability in the source and arborization pattern of the pulmonary blood supply. ${ }^{1-3}$ Treatment has evolved from palliative shunting or interruption of collateral arteries in the 1970s to reconstruction of the pulmonary arteries with unifocalization to the right ventricle with or without ventricular septal defect (VSD) closure. ${ }^{4-10}$ This progress has been related to the better characterization of the MAPCAs and native pulmonary arteries (NPAs) together with improvements in the surgical care of small infants. Classification of the pulmonary blood supply in patients with CHDs and MAPCAs is necessary to plan appropriate surgical management. However, the classification of pulmonary blood supply is difficult because of the complex variability in the morphology of the NPAs and MAPCAs. The aim of this study was to determine the influence of anatomic variables that characterize the pulmonary blood supply on outcome in patients who underwent surgical intervention for CHDs and MAPCAs at our institution.

\section{Patients and Methods}

Between January 1989 and December 2002, 167 patients with CHDs and MAPCAs were referred for treatment to the Diana Princess of Wales Children's Hospital, Birmingham, United Kingdom. Three (1.8\%) patients with univentricular connections declined operations and were not included in this study. All other patients referred were entered into the surgical program.

This study involved the retrospective review of hospital records and echocardiographic and cardiac catheterization data, as well as assessment of the current clinical status. For the purposes of analysis, the 30-day mortality and actuarial survival after the first operation and complete repair with VSD closure, as well as the actuarial freedom from surgical and cardiac catheter reintervention, were used as outcome measures. These were evaluated with regard to a series of morphologic variables that defined pulmonary blood supply.

All patients have been followed up either by a pediatric cardiologist in our own unit or in the patients' referring hospital. Clinical status was graded by using the New York Heart Association functional classification. Follow-up was complete, with a median interval of 5.8 years after the first operation (range, 1 day-23.4 years) and 3.9 years after complete repair (range, 1 day-12.9 years).

Of the 164 patients who underwent surgical intervention for CHDs with MAPCAs, 76 (47\%) were male. The median age at the time of the first operation was 10 months (range, 1 day-47 years), and $87(53 \%)$ were less than 1 year of age at the time of the first operation. The most common cardiac malformation was pulmonary atresia and VSD $(\mathrm{n}=153$ [93.3\%]). The remaining 11 patients had a variety of other diagnoses (Table 1). Four patients with pulmonary atresia and VSDs had additional cardiac anomalies, 3 with an anomalous left anterior descending coronary artery arising from the right coronary artery and 1 with partial anomalous
TABLE 1. Primary cardiac anatomy among patients with CHDs and MAPCAs

Pulmonary atresia and ventricular septal defect 153

Tetralogy of Fallot 5

Congenitally corrected transposition of the great arteries

Simple transposition of the great arteries

Pulmonary atresia and intact ventricular septum

Truncus arteriosus

Left atrial isomerism, atrioventricular septal defect, and total anomalous pulmonary venous drainage

pulmonary venous return to the superior vena cava. Thirty $(18 \%)$ patients had associated noncardiac anomalies. Of these, $22(73 \%)$ patients had the Di George syndrome with chromosome 22q11 microdeletion, although fluorescent in situ hybridization (FISH) was not routinely performed at our institution until 1995.

Each patient had a median number of 4 MAPCAs (range, 1-7). In the majority of patients $(n=161$ [98.2\%]), these originated from the descending thoracic aorta or the aortic arch. In $3(1.8 \%)$ patients the MAPCAs also arose from the right coronary artery. Twenty-five patients were initially treated at other centers. Eight patients had iatrogenic complications after these initial surgical procedures, which significantly altered our surgical strategy. The majority of patients $(n=138$ [84\%]) presented with varying degrees of cyanosis, whereas $26(16 \%)$ patients presented with congestive cardiac failure.

\section{Assessment and Classification of the Pulmonary Blood Supply}

Cardiac catheterization studies were analyzed to delineate the pulmonary blood supply and the intracardiac morphology and to collect haemodynamic data. NPAs were outlined by means of direct injection of MAPCAs through shunts or from retrograde pulmonary venous wedge studies. The vascular morphology was classified to allow for detailed analysis to relate these anatomic variables of the pulmonary blood supply to surgical outcomes.

First, 3 groups of NPA morphology were identified. In group I $(\mathrm{n}=111)$ native intrapericardial pulmonary arteries were present. In group II $(\mathrm{n}=30)$ intrapericardial NPAs were absent, but there were confluent intrapulmonary pulmonary arteries in one or both lungs. In group III $(n=23)$ both the intrapericardial pulmonary arteries and the confluent intrapulmonary pulmonary arteries were absent.

Second, central and distal pulmonary artery size was classified as adequate if greater than $75 \%$ of predicted size, hypoplastic between $50 \%$ and $75 \%$, and very hypoplastic if smaller than $50 \%$ of expected size. ${ }^{11}$

Third, MAPCAs were classified as large if in excess of $2 \mathrm{~mm}$ in diameter, medium if between 1 and $2 \mathrm{~mm}$ in diameter, and small if less than $1 \mathrm{~mm}$ in diameter. ${ }^{11}$

Using these rules, we could estimate pulmonary blood supply in patients in whom either the NPAs or MAPCAs constituted the predominant pulmonary blood source. It was more difficult to assess pulmonary blood supply when NPAs and MAPCAs combined with a varying degree of dual blood supply. To allow for 


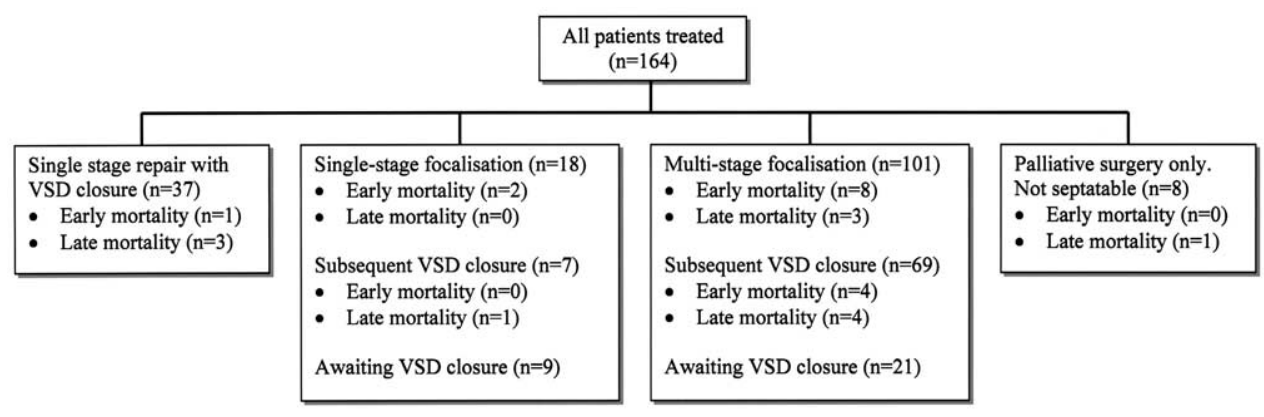

Figure 1. Surgical algorithm for treatment of patients with CHDs and MAPCAs.

ease of statistical analysis among these patients, we made an estimation of the overall caliber of distal pulmonary blood supply, which encompassed the size of the NPAs and MAPCAs and the presence and extent of dual blood supply. Pulmonary blood supply was thus classified as adequate, medium, or small.

This classification system was, in part, subjective. Nevertheless, we believed that it provided the best approximation of the pulmonary blood supply, which would allow more detailed statistical analysis of outcome.

\section{Surgical Intervention}

The technical aspects of surgical intervention have evolved over the period of review. Many aspects are similar to those described in other centers. ${ }^{12-23}$ Our first single-stage repair with VSD closure was performed in 1991, and when possible, this is our procedure of choice. Primary focalization of the reconstructed pulmonary arteries and MAPCAs to the right ventricle with a valved conduit is our favored method of restoring pulmonary artery continuity, even when the VSD cannot be closed at the initial procedure. A restrictive conduit from the right ventricle to the pulmonary artery is used in patients in whom the VSD cannot be closed (ie, similar to the VSD pulmonary stenosis situation, such that the distal pulmonary arteries are not subjected to high pressure or excessive blood flow). In addition, this technique facilitates subsequent catheterization and surgical intervention to enlarge the distal pulmonary arteries. Palliative unifocalization with a systemic shunt is still occasionally used, but this is now unusual in our practice.

Mobilization and delineation of the MAPCAs and often the proximal NPAs is usually achieved through a short thoracotomy on the side of the descending thoracic aorta. This approach provides good surgical exposure of the mediastinal structures and clear delineation of the NPAs within the pulmonary fissures. There is thus less risk of damage to the phrenic or vagus nerves or the mediastinal vessels. This is then followed by a midline sternotomy giving access for reconstruction of the vessels by using hypothermic cardiopulmonary bypass with periods of circulatory arrest if required. The distal vessels are sometimes controlled with small Yarsargil aneurysm clips (Aesculap AG \& Co KG, Tuttlingen, Germany) to restrict the periods of circulatory arrest. Anastomoses between the pulmonary artery tissue and the collateral tissue are preferred but not always possible. Patch enlargement of the vessels is generally achieved by using pulmonary homograft patch mate- rial, although polytetrafluroethylene* tube conduits and Medtronic Contegra pulmonary valved conduits (Medtronic UK Ltd, Watford, United Kingdom) are used when necessary.

The decision whether to close the VSD can be difficult. We prefer to depend on the preoperative evaluation of the vessels together with a subjective evaluation of the success of the anastamosis and reconstruction at the time of the operation to determine whether the VSD can be closed. Tetralogy of Fallot can be repaired to a single lung circulation with a low postoperative right ventricular/left ventricular (RV/LV) pressure ratio. In patients with CHDs and MAPCAs, we consider 15 pulmonary segments (ie, equivalent to $1 \frac{1}{2}$ lungs) as safe for complete repair with VSD closure. If in doubt, the VSD is not closed.

Aprotinin (Ferring Pharmaceuticals A/S, Copenhagen, Denmark) and tissue glues, such as Beriplast $\mathrm{P}$ (Aventis Behring $\mathrm{GmbH}$, Marburg, Germany), are used to help with hemostasis. In addition, the native pericardial envelope is carefully preserved and closed with a Supple Peri-Guard pericardial membrane (Biovascular Inc, Saint Paul, Minn) to facilitate reoperative procedures. We have a low threshold for leaving the sternum open, although we try to close the skin in the immediate postoperative period.

Postoperatively, the majority of patients have a cardiac catheterization study before discharge to evaluate the quality and completeness of MAPCA recruitment and to plan further surgical or catheter intervention. Furthermore, all patients are readmitted within 6 months after the operation for another cardiac catheterization study, and any residual abnormalities are aggressively treated at that time.

The surgical management of the 164 patients is summarized in Figure 1. Essentially, 4 main management strategies have evolved: single-stage repair with VSD closure, single-stage unifocalization to the right ventricle, multistage focalization, and a palliative operations without the prospect of VSD closure.

\section{Statistical Analysis}

Data have been examined by means of analysis of variance with a commercial statistical software package (SPSS for Windows, version 11; SPSS Inc, Chicago, Ill). Continuous variables are expressed as medians and ranges, and comparative univariate analyses have been made with the Mann-Whitney $U$ test or the

*Gore-Tex tube conduits, registered trademark of W. L. Gore \& Associates, Inc, Newark, Del. 


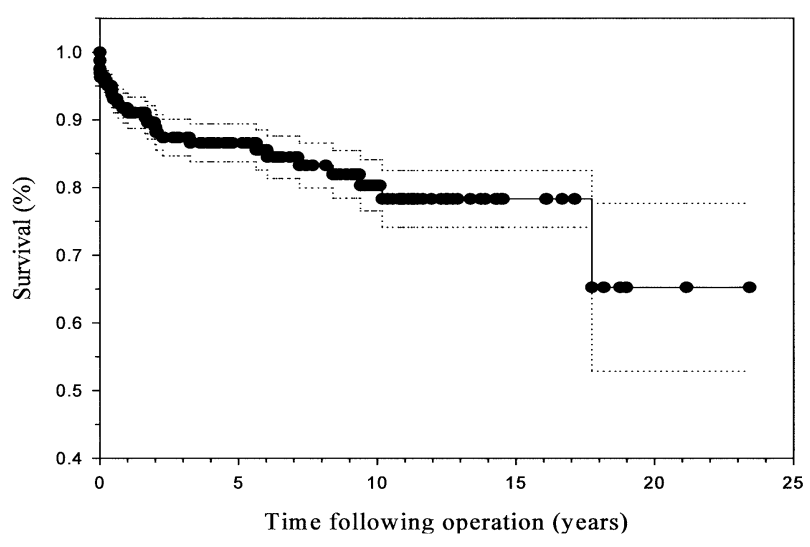

Figure 2. Kaplan-Meier estimated survival after the first operation ( \pm 1 SEM).

Wilcoxon signed- rank test. Binomial or ordinal data are expressed as percentages, and comparative univariate analyses have been made with the $\chi^{2}$ test, the 2-sided Fisher exact test, or binomial logistic regression, as appropriate.

The effect of the morphologic variables on outcome was tested by using univariate and multivariate analyses. Univariate analyses of early outcome measures have been made with the $\chi^{2}$ test, the 2 -sided Fisher exact test, and binomial logistic regression. Variables with a $P$ value of less than or equal to .1 were included in a stepwise logistic regression model. Results of these multivariate analyses have been expressed as odds ratios with $95 \%$ confidence intervals (CIs) for variables with a $P$ value of less than .05 . Actuarial survival, freedom from reoperation, and freedom from reintervention were estimated by using the Kaplan-Meier product limit method. These results have been expressed as a probability estimate \pm 1 SEM. Univariate analyses of actuarial outcome measures have been made with the log-rank test. Variables with a $P$ value of less than or equal to .1 were included in a stepwise Cox regression analysis. Results of these multivariate analyses have been expressed as likelihood ratios (LRs) with $95 \%$ CIs for variables with a $P$ value of less than .05 .

\section{Results}

The 30-day mortality after the first operation for all 164 patients was $3.7 \%(n=6)$. There were 21 late deaths after the first operation. Actuarial survival was $92 \% \pm 2 \%$ at 1 year, $87 \% \pm 2 \%$ at 5 years, $80 \% \pm 4 \%$ at 10 years, and $65 \%$ $\pm 12 \%$ at 20 years postoperatively (Figure 2 ).

Multivariate analysis identified one factor that independently increased the risk of early mortality after the first operation. Patients in whom MAPCAs were left in the systemic circulation had an increased risk of early mortality after the first operation (LR, 12.5; 95\% CI, 2.0-80.4; $P<.008$ ).

Multivariate analysis identified pulmonary artery morphology as the only variable that independently increased the actuarial risk of mortality after the first operation $(P=$ .01). Compared with patients with intrapericardial NPAs (group I), patients without confluent NPAs (group III) had

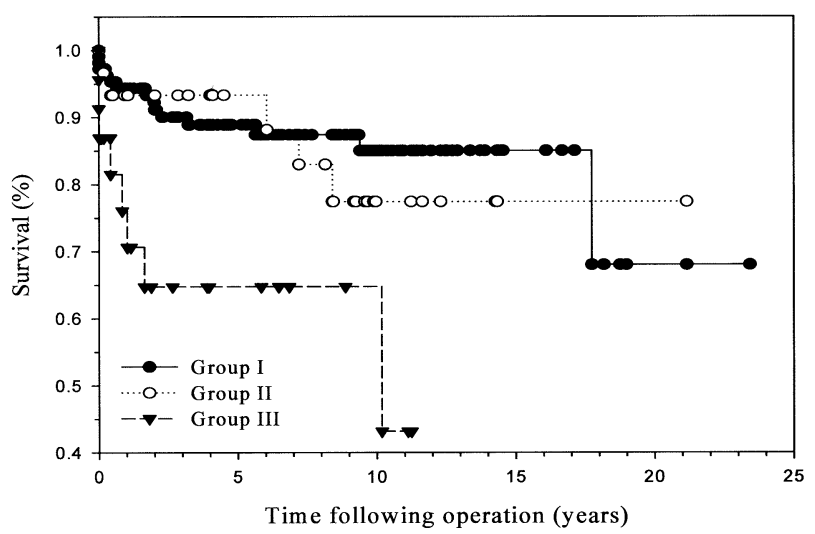

Figure 3. Kaplan-Meier estimated survival after the first operation according to the NPA morphology ( $P=.002$, log-rank test).

an increased risk (LR, 7.8; 95\% CI, 2.8-21.7; $P<.001)$. By comparison, patients with confluent intrapulmonary NPAs (group II) did not have an increased risk (LR, 1.7; 95\% CI, 0.6-4.9; $P=.32$; Figure 3).

The 30-day mortality after single-stage or multistage correction with VSD closure was $4.4 \%(n=5)$. There were 8 late deaths after septation. The actuarial survival was $91 \%$ $\pm 3 \%$ at 1 year, $88 \% \pm 3 \%$ at 5 years, and $86 \% \pm 4 \%$ at 10 years after the operation (Figure 4). Surgical strategy, single-stage or multistage repair, had no influence on early mortality or actuarial survival after completion $(P=.98)$.

Among the patients who underwent complete repair with VSD closure, the median $\mathrm{RV} / \mathrm{LV}$ pressure ratio during the perioperative period was 0.6 (range, 0.3-0.9).

Multivariate analysis identified the pulmonary artery morphology as the only variable that independently increased the risk of early mortality after complete correction with VSD closure $(P=.04)$. Compared with patients in group I, patients in group III were associated with an increased risk (LR, 75.1; 95\% CI, 3.1-1802.7; $P=.008$ ). Patients in group II were not associated with an increased risk (LR, 7.4; 95\% CI, 0.3-187.3; $P<.23$ ).

Multivariate analysis identified pulmonary artery morphology as the only variable that independently increased the actuarial risk of mortality after septation $(P=.04)$. Compared with patients in group I, patients in group III had an increased risk (LR, 4.9; 95\% CI, 1.2-20.5; $P=.03$ ). By comparison, patients in group II did not have an increased risk (LR, 3.1; 95\% CI, 0.9-11.0; $P=.07$; Figure 5).

Five $(4.4 \%)$ patients underwent early surgical or catheter reintervention after complete correction with VSD closure. A further 36 patients required late reintervention during the follow-up period. The actuarial freedom from reintervention in the septated group was $77 \% \pm 2 \%$ at 1 year, $62 \% \pm 5 \%$ at 5 years, and $46 \% \pm 8 \%$ at 10 years postoperatively (Figure 6). 


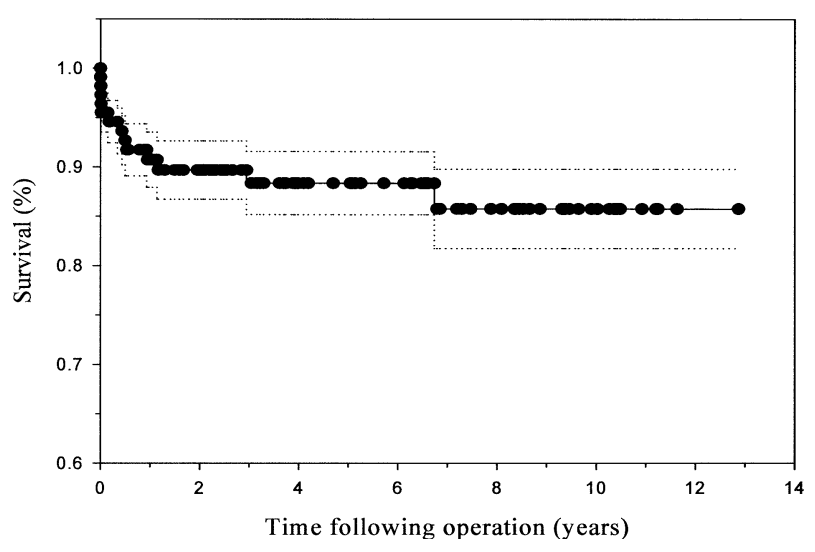

Figure 4. Kaplan-Meier estimated survival after complete correction with VSD closure ( \pm 1 SEM).

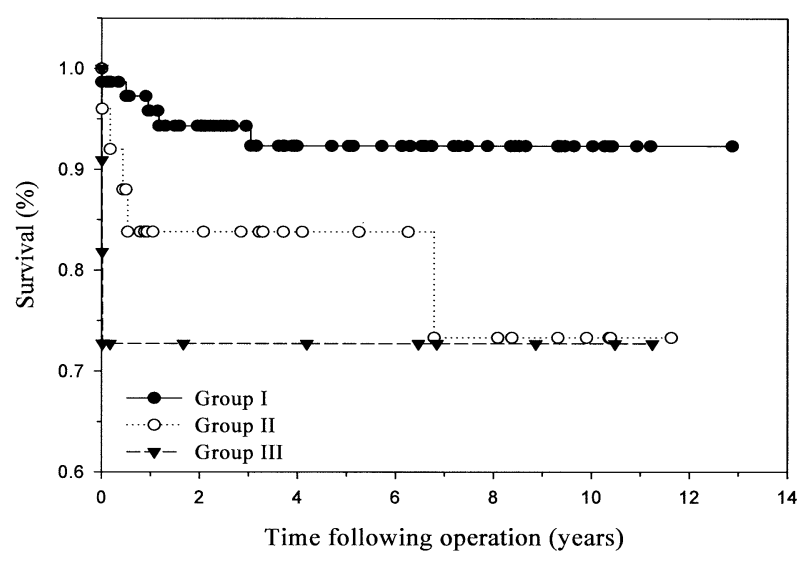

Figure 5. Kaplan-Meier estimated survival after complete correction with VSD closure according to the NPA morphology $(P=.03$, log-rank test).

Multivariate analysis identified one variable that was associated with the risk of surgical or catheter reintervention after complete correction with VSD closure: the caliber of the distal pulmonary vasculature $(P=.002)$. Compared with patients with adequate-sized pulmonary vasculature, patients with small pulmonary vasculature had an increased risk (LR, 6.2; 95\% CI, 2.1-18.2; $P=.001$ ). Patients with medium-sized pulmonary vasculature were not associated with an increased risk (LR, 2.2; 95\% CI, 0.5-9.5; $P=.3$; Figure 7).

\section{Discussion}

Analysis of surgical results of CHDs with MAPCAs is difficult because of the extreme variability of the NPA and MAPCA supply to the lungs. We have devised a classification of the pulmonary blood supply to determine the influence of the pulmonary artery morphology on surgical results. Other classifications have concentrated on the intra-

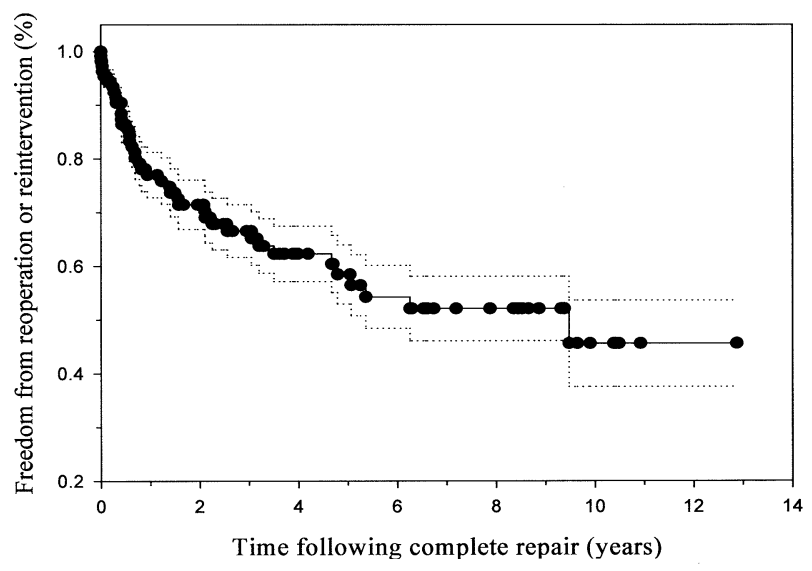

Figure 6. Kaplan-Meier estimated freedom from surgical or catheter reintervention after complete correction with VSD closure ( \pm 1 SEM).

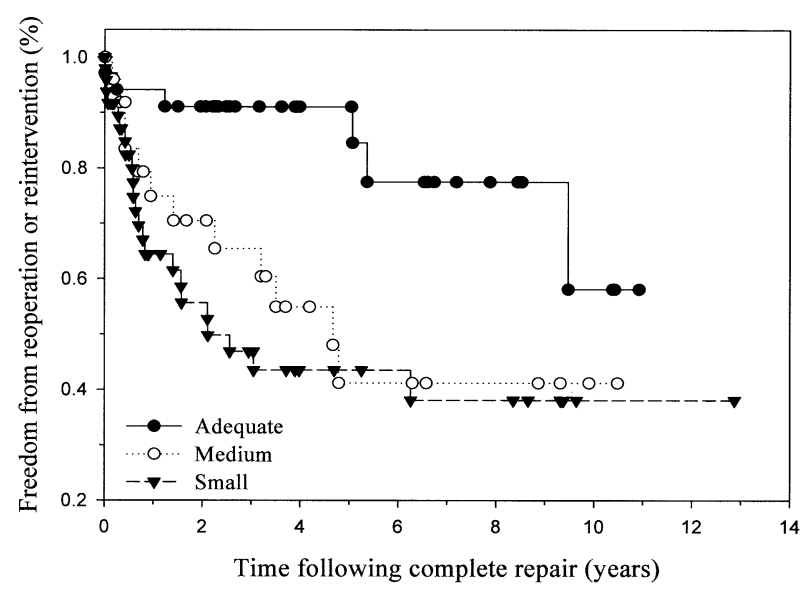

Figure 7. Kaplan-Meier estimated freedom from surgical or catheter reintervention after complete correction with VSD closure according to the overall pulmonary blood supply $(P=.002$, log-rank test).

pericardial pulmonary arteries as to whether they are present, hypoplastic, or absent. We believed that a cornerstone of a successful operation could be the presence of confluent intrapulmonary pulmonary arteries. In fact, we have shown this to be the case in our analysis. Thus patients in groups I and II fair significantly better than those in group III. We also note that attempts to reconstruct NPAs to overcome this lack of continuity do not seem to alter the surgical results.

The mortality for surgical intervention after the first operation $(3.7 \%)$ and after either primary or secondary repair with VSD closure $(4.4 \%)$ is satisfactory and compares with the results of other reported series. ${ }^{12-23}$ However, it is the actuarial curves that provide a better insight into the ability to affect the natural history of this condition. Thus at 
10 years, $80 \% \pm 4 \%$ of all 164 patients and $86 \% \pm 4 \%$ of the septated group are alive. The natural history of this condition for purposes of comparison is difficult to elucidate. However, Bull and colleagues, ${ }^{24}$ in a group of patients of similar age, noted a $50 \%$ mortality at 1 year of age in patients with CHDs and MAPCAs. Thus it seems a considerable improvement for these patients has been achieved.

However, the need for reintervention with cardiac catheterization or surgical intervention to dilate or occlude vessels and to enlarge pulmonary arteries or change valve conduits continues to be a problem, and thus the freedom for any reintervention in the septated group at 10 years was only $46 \% \pm 8 \% .^{25,26}$ Perhaps not surprisingly, patients with small-sized pulmonary arteries had a 6-fold greater risk of reintervention when compared with patients having adequate-sized vasculature. In addition, we have only achieved a median $\mathrm{RV} / \mathrm{LV}$ pressure ratio of 0.6 after the operation. This merely emphasizes the need to optimize the pulmonary artery size at surgical repair.

Finally, we could discern no statistical difference in risk between a primary repair with VSD closure or a staged repair with VSD closure at a later date.

We have to acknowledge that this analysis is based on a compilation of data from cardiac catheter operative records, all of which were carefully reviewed, but naturally a subjective element enters into such a classification. However, it does allow an analysis of data that would otherwise not be possible.

Some implications of this study are that we can be selective in our surgical approach for patients, either applying a primary repair with VSD closure or a staged repair with VSD closure because there is no increased risk between the 2 approaches. We should aim for more careful intrapulmonary reconstruction of pulmonary arteries to remove the risk inherent and noted in this article in the group III patients in comparison with the patients in groups I and II. Finally, we note that it seems that the important vessels are within the lung itself and that the intrapericardial vessels can be reconstructed and changed as necessary without increasing the risk to the patient but that the intrapulmonary vessels are best treated at the time of the primary procedure. The presence of confluent intrapulmonary vessels has a statistically significant positive effect on successful outcome in patients with MAPCAs.

\section{References}

1. Ramsay JM, Macartney FJ, Haworth SG. Tetralogy of Fallot with major aortopulmonary collateral arteries. Br Heart J. 1985;53:167-72.

2. Faller K, Haworth SG, Taylor JF, Macartney FJ. Duplicate sources of pulmonary blood supply in pulmonary atresia with ventricular septal defect. Br Heart J. 1981;46:263-8.

3. Haworth SG, Macartney FJ. Growth and development of pulmonary circulation in pulmonary atresia with ventricular septal defect and major aortopulmonary collateral arteries. Br Heart J. 1980;44:14-24.

4. Rodefeld MD, Reddy VM, Thompson LD, Suleman S, Moore PC,
Teitel DF, et al. Surgical creation of aortopulmonary window in selected patients with pulmonary atresia with poorly developed aortopulmonary collaterals and hypoplastic pulmonary arteries. $J$ Thorac Cardiovasc Surg. 2002;123:1147-54.

5. Murthy KS, Rao SG, Naik SK, Coelho R, Krishnan US, Cherian KM. Evolving surgical management for ventricular septal defect, pulmonary atresia, and major aortopulmonary collateral arteries. Ann Thorac Surg. 1999;67:760-4.

6. Reddy VM, Petrossian E, McElhinney DB, Moore P, Teitel DF, Hanley FL. One-stage complete unifocalization in infants: when should the ventricular septal defect be closed? J Thorac Cardiovasc Surg. 1997;113:858-66.

7. Iyer KS, Mee RB. Staged repair of pulmonary atresia with ventricular septal defect and major systemic to pulmonary artery collaterals. Ann Thorac Surg. 1991;51:65-72.

8. Iyer KS, Varma M, Mee RB. Use of azygos vein as interposition graft for surgical unifocalization of pulmonary blood supply. Ann Thorac Surg. 1989;48:776-8.

9. Sullivan ID, Wren C, Stark J, de Leval MR, Macartney FJ, Deanfield JE. Surgical unifocalization in pulmonary atresia and ventricular septal defect. A realistic goal? Circulation. 1988;78(suppl):III5-13.

10. Haworth SG, Rees PG, Taylor JF, Macartney FJ, de Leval M, Stark J. Pulmonary atresia with ventricular septal defect and major aortopulmonary collateral arteries. Effect of systemic pulmonary anastomosis. Br Heart J. 1981;45:133-41.

11. Murthy KS, Krishnanaik S, Coelho R, Punnoose A, Arumugam SB, Cherian KM. Median sternotomy single stage complete unifocalization for pulmonary atresia, major aorto-pulmonary collateral arteries and VSD-early experience. Eur J Cardiothorac Surg. 1999;16:21-5.

12. Tchervenkov CI, Roy N. Congenital Heart Surgery Nomenclature and Database Project: pulmonary atresia-ventricular septal defect. Ann Thorac Surg. 2000;69(suppl):S97-105.

13. Johnson RJ, Sauer U, Buhlmeyer K, Haworth SG. Hypoplasia of the intrapulmonary arteries in children with right ventricular outflow tract obstruction, ventricular septal defect, and major aortopulmonary collateral arteries. Pediatr Cardiol. 1985;6:137-43.

14. Lofland GK. The management of pulmonary atresia, ventricular septal defect, and multiple aorta pulmonary collateral arteries by definitive single stage repair in early infancy. Eur J Cardiothorac Surg. 2000; 18:480-6.

15. Cho JM, Puga FJ, Danielson GK, Dearani JA, Mair DD, Hagler DJ, et al. Early and long-term results of the surgical treatment of tetralogy of Fallot with pulmonary atresia, with or without major aortopulmonary collateral arteries. J Thorac Cardiovasc Surg. 2002;124:70-81.

16. Cherian KM, Murthy KS. Single-stage complete unifocalization and repair for tetralogy of Fallot, pulmonary atresia, and major aortopulmonary collateral arteries. Adv Card Surg. 2001;13:89-106.

17. Reddy VM, McElhinney DB, Amin Z, Moore P, Parry AJ, Teitel DF, et al. Early and intermediate outcomes after repair of pulmonary atresia with ventricular septal defect and major aortopulmonary collateral arteries: experience with 85 patients. Circulation. 2000;101: 1826-32.

18. Carotti A, Di Donato RM, Squitieri C, Guccione P, Catena G. Total repair of pulmonary atresia with ventricular septal defect and major aortopulmonary collaterals: an integrated approach. J Thorac Cardiovasc Surg. 1998;116:914-23.

19. McElhinney DB, Reddy VM, Hanley FL. Tetralogy of Fallot with major aortopulmonary collaterals: early total repair. Pediatr Cardiol. 1998; 19:289-96.

20. Tchervenkov CI, Salasidis G, Cecere R, Beland MJ, Jutras L, Paquet $\mathrm{M}$, et al. One-stage midline unifocalization and complete repair in infancy versus multiple-stage unifocalization followed by repair for complex heart disease with major aortopulmonary collaterals. J Thorac Cardiovasc Surg. 1997;114:727-35.

21. Tireli E, Basaran M, Kafali E, Soyler I, Camci E, Dayioglu E. Single-stage unifocalization and correction with median sternotomy in complex pulmonary atresia. Cardiovasc Surg. 2002;10:600-4.

22. Metras D, Chetaille P, Kreitmann B, Fraisse A, Ghez O, Riberi A. Pulmonary atresia with ventricular septal defect, extremely hypoplastic pulmonary arteries, major aorto-pulmonary collaterals. Eur J Cardiothorac Surg. 2001;20:590-6. 
23. Reddy VM, Liddicoat JR, Hanley FL. Midline one-stage complete unifocalization and repair of pulmonary atresia with ventricular septal defect and major aortopulmonary collaterals. J Thorac Cardiovasc Surg. 1995; 109:832-44.

24. Bull K, Somerville J, Ty E, Spiegelhalter D. Presentation and attrition in complex pulmonary atresia. J Am Coll Cardiol. 1995;25:491-9.

25. Brown SC, Eyskens B, Mertens L, Dumoulin M, Gewillig M. Percutaneous treatment of stenosed major aortopulmonary collaterals with balloon dilatation and stenting: what can be achieved? Heart. 1998; 79:24-8.

26. Chetaille P, Fraisse A, Ghez O, Kreitmann B, Voisin M, Aubert F, et al. Rehabilitation of hypoplastic pulmonary arteries and anatomic correction of pulmonary atresia with interventricular communication. Arch Mal Coeur Vaiss. 2001;94:446-51.

\section{Discussion}

Dr Gary K. Lofland (Kansas City, Mo). I do not have any questions for you, so you are off the hook and can relax a little bit. I do have some complimentary comments though, particularly concerning some aspects of the article.

I suppose I was asked to discuss this article because of a certain experience and familiarity with this disease. For reasons we are attempting to understand, we seem to have a disproportionately high incidence of pulmonary atresia in Kansas City, and that incidence appears to be increasing. In 2001, we had 52 newborns with pulmonary atresia in its various manifestations: intact septum, VSD, VSD with MAPCAs, and patients with complex heterotaxy with single ventricles. In 2002, it grew to 63 newborns, and in the first 4 months of this year, we have had 35 patients, giving us about 1 to 2 new patients with pulmonary atresia per week.

With this volume of new patients, beginning in 1997, we adopted what we believe is a very aggressive approach that is very similar to that outlined by the authors of this article, except that we have attempted to accelerate the process just a bit.

All babies presenting with this diagnosis in our institution undergo cardiac catheterization as a newborn. This enables documentation of nonductile dependency, definition of the NPAs if present, and description of the collateral arteries.

We then bring these babies back at 3 months of age and recatheterize them, looking for changes in the NPAs and the collateral arteries. It is amazing how much growth of any NPAs that happen to be present can occur in the first 3 months.

Failure to see growth during that time is disappointing. A $1-\mathrm{mm}$ pulmonary artery at birth is still a 1-mm NPA at 3 months, and this means it is going to be a long day in the operating room.

We initiate surgical intervention immediately after this catheterization, and that intervention is delayed only by intercurrent viral illness. We try not to do these during respiratory syncytial virus season.

I noticed in your article that you used deep hypothermia and circulatory arrest. Although we would naturally hold that perfusion technique in reserve, we have chosen instead to use a vacuumassisted normothermic bypass and have been very satisfied with the degree of cardiopulmonary decompression we get with that technique. Therefore I would propose that as an alternative. That perfusion technique has been described by my chief perfusionist in perfusion journals.

Now in your article, you have mentioned the association of 22Q11 deletion patterns and conal truncal defects. This association was also mentioned in the congenital course yesterday, but microdeletions of the 22 nd chromosome are seen in only about $25 \%$ to $30 \%$ of these patients, and therefore our knowledge of this is still very, very rudimentary, although it is fascinating.

Driven in part by the numbers of patients we see with this disease and active and willing sections of molecular genetics and clinical pharmacology, about 4 months ago, we acquired and developed the technology to perform a microarray analysis for a little over 17,000 different genes by using very small tissue samples. I would like to share some of that preliminary data with you because it is mentioned in your article.

In patients with pulmonary atresia, we have found genetic expression occurring in the pulmonary arteries that seems to be very different than the genetic expression occurring in myocardium, pericardium, and thymus in the same patients and in normal patients with no cardiac disease.

One thinks of genetic expression as being uniform in all the tissues in an individual, but that is proving to not be the case. This variability of expression seems to be single-nucleotide polymorphisms (SNPS).

If these preliminary findings prove to be true, their significance lies in the fact that SNPS can be manipulated. Indeed, the manipulation of single-nucleotide polymorphisms is the foundation of the knockout mouse models that are used in pharmacokinetic and other studies. We now know that the genes in these animal models can be turned on, and they can be turned off.

It is intriguing to think that in the future, the management of these patients might include the ability to turn genes on or off that are responsible for the growth and development, or lack thereof, of pulmonary arteries, thereby possibly giving us something a bit better with which to work.

This is an excellent article, and the authors should be congratulated for quantitatively demonstrating something that those of us who care for numbers of these patients have qualitatively understood or at least suspected.

Outcomes in these patients are not affected at all by the inability to close the VSD at the time of unifocalization and right ventricular PA connection and is very much dependent on the presence and size of the NPAs.

Dr R. Ungerleider. Gary, before you leave the microphone, just in case anybody wants to look up the reference, is it Gary Grist who is your chief perfusionist?

Dr Lofland. Yes.

Dr Griselli. I would like to make a comment regarding some data on the article and on the presentation.

First of all, our classification in terms of single-stage and multistage repair is a bit different from other proposals in the literature. In our article and in our presentation, single-stage repair means one operation only. It means that in the same operation we unifocalize and close the VSD. Of course, there is this matter of nomenclature difference.

Basically, single-stage unifocalization happens in different patients, but this has been included in a multistage repair because there is more than one anesthetic and more than one operation. Included is multistage repair, which involves those patients who had palliative surgery without unifocalization and subsequently had a complete single-stage unifocalization with or without closure of the VSD. Therefore the number is a bit different than the one shown by our classification, and we tried to do it in a different way. 
Regarding the Di George syndrome, we had 222 patients identified by means of the FISH test; in our institution the FISH test was started routinely for conal truncal abnormalities around January 1995 . Therefore probably we missed something, but I think this is a common problem for other workers I have seen in literature.

Dr Thomas L. Spray (Philadelphia, $P a$ ). I just had a question, and it might be in your article, but in your new classification, when you are talking about confluent, I assume, intraparenchymal pulmonary arteries, you mentioned that it is unilateral or bilateral.

Was there any difference in terms of outcome, whether it was unilateral or bilateral, and did that determine whether you tried to do a single-stage unifocalization or a staged unifocalization?

Dr Griselli. No, there was no difference between unilateral or bilateral confluent intrapulmonary PAs.

There were differences between unilateral and bilateral compared with the MAPCAs, definitely in outcome. The patient had only MAPCAs. That was the only difference noted, not between unilateral or bilateral, no.

Dr Adriano Carotti (Rome, Italy). Did you find any difference between the single-stage approach and the multistage approach either in terms of hemodynamic results, namely, the RV/LV pressure ratio after VSD closure, or of major perioperative morbidity, such as a paralysis of the phrenic nerve.

Furthermore, concerning 22Q11 microdeletion, which occurred in our experiences as much as $40 \%$ of cases and related significantly with postsurgical prognosis, I would like to know whether, in your series, chromosome 22Q11 microdeletion affected perioperative mortality, morbidity, or both at all.

Dr Griselli. There was no difference in terms of complication for different groups. We had 21 major complications, complications that required intervention, and there were no differences within the 3 groups.

Regarding the microdeletion, again, there were no differences among the 3 groups, although we reviewed the data from another point of view, because this is just an aspect of the MAPCA surgery. Our idea is that we want to explain why some patients who basically had a better anatomy, such as intrapulmonary pulmonary arteries, require more reoperation, but we are looking at this for a further study.

Dr Antonio F. Corno (Lausanne, Switzerland). What are the consequences of your study? On the basis of the observation you reported, did you change any policy in your approach to these patients? Are you considering any change, particularly in the group of patients with MAPCAs only?

Dr Griselli. There is no change in terms of the operation, but what before was important for us, like finding the intrapericardial pulmonary arteries in terms of results, now we focus more on finding confluence at the intrapulmonary level, which seems to be a more important thing for a surgeon to find the confluence between the chest and the hilum. Then you can join them up centrally, as you like.

But more important is not just what you can find inside the pericardium but what you can find in the hilum of the lungs. If you find a good confluence, it is a good prognostic factor, even if you do not have intrapericardial PAs.

\section{Targeted}

The Journal of Thoracic and Cardiovascular Surgery gives you two tables of contents. The condensed table of contents tells you at a glance what topics and authors are presented each month. The expanded table of contents gives you a brief abstract of each article. You select only those articles of most interest to you for further reading. 